\title{
Lusioersily
}

\section{Gasification of Waste Medium Density Fibreboard as a Route to Power Generation}

Williams, BC., Mcllveen-Wright, D., \& Rezvani, S. (2003). Gasification of Waste Medium Density Fibreboard as a Route to Power Generation. Developments in Chemical Engineering and Mineral Processing, 11(1-2), 55-66. https://doi.org/10.1002/apj.5500110206

Link to publication record in Ulster University Research Portal

\section{Published in:}

Developments in Chemical Engineering and Mineral Processing

Publication Status:

Published (in print/issue): 01/01/2003

DOI:

10.1002/apj.5500110206

\section{Document Version}

Author Accepted version

\section{General rights}

Copyright for the publications made accessible via Ulster University's Research Portal is retained by the author(s) and / or other copyright owners and it is a condition of accessing these publications that users recognise and abide by the legal requirements associated with these rights.

\section{Take down policy}

The Research Portal is Ulster University's institutional repository that provides access to Ulster's research outputs. Every effort has been made to ensure that content in the Research Portal does not infringe any person's rights, or applicable UK laws. If you discover content in the Research Portal that you believe breaches copyright or violates any law, please contact pure-support@ulster.ac.uk. 


\section{Gasification of Waste Medium Density Fibreboard as a Route to Power Generation}

\section{B.C. Williams*, D. McIlveen-Wright and S. Rezvani}

NICERT, University of Ulster, Coleraine BT52 1SA,

Northern Ireland, UK

Medium density fibreboard (MDF) processing in Northern Ireland generates about 40 tonnes of MDF dust per week, which gives significant disposal problems and costs. The overall aim of this project was to develop an environmentally friendly, energy efficient and economically acceptable means of generating "green" electricity from MDF dust.

The project is based on using a down draught fixed bed gasifier with a modified diesel engine generator. Before MDF dust can be used in the gasifier it must first be briquetted. Although many equipment manufacturers claim to be able to briquette MDF dust, only two were able to prove this capability, PLC Products and Kahl. Trials were arranged and as a result a B10 Bio-Compactor was purchased and installed. However, good quality briquettes could not be produced reliably due in part to a lack of experience in operating the B10 Bio-Compactor and in part to mechanical failures. Changes were made to the B10 Bio-Compactor to improve its mechanical integrity and further trials will be performed to establish the conditions required to make MDF briquettes reliably.

In order to provide MDF briquettes for the gasification trials it was decided to use MDF off-cuts sawn to the correct size. The project team was happy that these off-cuts possess very similar properties to the briquettes produced by the B10 Bio-Compactor and would therefore give very similar gasification behaviour. The gasification trials were very successful, with 8 hours continuous operation without problems. The calorific value of the fuel gas produced was $4.8 \mathrm{MJ} / \mathrm{nm}^{3}$, which is almost identical to that obtained from normal hardwood chip fuel. From the gasifier a mixture of diesel and MDF fuel gas was fed to the diesel engine generator. This is the normal practice for these types of engines in order to maintain smooth and efficient combustion. No problems were experienced when changing over from diesel to the fuel gas mixture.

* Author for correspondence. 


\section{Background Information}

Medium Density Fibreboard (MDF) board is a relatively new product introduced to the building industry within the past 10 years. It is a new generation particleboard generated to satisfy the demand for a wood based material that is available in sheet form and is easily machined and finished. Its main uses are for kitchen unit production and internal wall panelling. MDF is manufactured from the thinning and cuttings of Lodgepole pine and Sitka spruce trees. The trees are machined into a fine dust and bonded together using a formaldehyde resin. The particle size of the wood dust varies between 100 to 750 microns. In MDF production the bonding is achieved with adhesive application rates in the region of 6 to $12 \%$ of adhesive relative to dry wood weight. In MDF the fibres are thinner than in other industrial wood engineered products, thus the internal surface area is increased and the amount of adhesive is also increased to produce a product of sufficient strength. The product is a solid board with a density of $750 \mathrm{~kg} / \mathrm{m} 3$ and a uniform structure. It is this structure that makes MDF very suitable for architectural mouldings as it benefits over traditional timber by not having any defects over the length of the sheet and the machined finish is very consistent. This is not achievable with traditional timber due to the knots, splits and shakes, which cannot be removed or eliminated.

In Northern Ireland SAM Ltd is the largest MDF processing company and they generate about 40 tonnes of dust per week. To remove the dust from each of the cutting and machining processes a vacuum system is used to suck the dust from the point of generation through extract ducts to a filter. In the filter the dust is removed from the air stream and conveyed to a collection point, from where it is removed by a waste disposal company and dumped. It is expected that there will be a rapid expansion in the use of MDF and therefore in the generation of dust. MDF dust is a renewable energy source that could be used for generating heat and electric power. Conventional entrained flow burners could be used to provide low-grade heat for paint drying and space heating. However the need for heat is limited and seasonal and in general the quantity of MDF dust available far exceeds the requirement for low-grade heat. MDF processing uses a substantial quantity of electricity to drive the wood working machines and extraction fans and therefore this opens up the possibility for a combined heat and power system utilising the MDF dust.

An alternative technology, gasification of the MDF dust to produce a low calorific value fuel gas, which can then be used to drive a modified diesel engine, is a potentially attractive proposition as the power generation efficiency is higher and the heat to power ratio lower. This technology has been demonstrated in Northern Ireland using wood chips, and indeed it is fair to say that Northern Ireland is a World leader in this technology. However this gasification technology is not suitable for feedstocks with a fine particle size. Therefore in order to gasify the MDF dust it must first be briquetted. Briquetters are commercially available for a wide range of feed materials, including wood dusts. However, the mechanical properties of the pellets/briquettes produced from wood dust have not been demonstrated as being suitable for gasification.

The overall aim of this project therefore is to develop an environmentally friendly, energy efficient and economically acceptable means of generating "green" electricity from MDF dust based on use of gasification and modified diesel engine technologies. 


\section{Feedstock Specification for Fixed Bed Gasifiers}

The gasifier selected is an air blown fixed bed downdraft gasifier that operates slightly above atmospheric pressure. Whilst these types of gasifiers were invented many decades ago, and were used extensively during World War II, when imported liquid transport fuels were not available, they have only recently been resurrected in the quest for small-scale power generation from renewable energy sources, such as biomass and wood waste. With regard to feedstock size for these gasifiers the majority (>95\%) of the material should be between $10 \mathrm{~mm}$ and $100 \mathrm{~mm}$ in size, there should be very little fine material $(<5 \mathrm{~mm})$ as this will restrict air flow through the bed and create excessive pressure drops and there should be no material greater than $150 \mathrm{~mm}$, as this could cause bridging and blocking of feeders. The moisture content should be less than $50 \%$ on a wet bas is as higher moisture contents will reduce the quality of the fuel gas and reduce the heat output from the CHP plant. With regard to carbonisation performance it is crucial for this type of gasifier that the feedstock produces a good solid block of charcoal in the reduction zone so that the carbon dioxide and water generated in the drying, devolatisation and combustion zones are efficiently reduced to carbon monoxide and hydrogen. Therefore the MDF dust and briquettes will be assessed against these three parameters.

The average particle size for the MDF dust was determined to be in the region of 100-700 microns $(0.1-0.7 \mathrm{~mm})$. The dust has a similar look and consistency of talcum powder and is much different to traditional wood sawdust, which has a particle size of $1-3 \mathrm{~mm}$. Therefore the MDF dust cannot be used without some form of briquetting. The briquettes should be between $10 \mathrm{~mm}$ and $100 \mathrm{~mm}$ in size and importantly the briquette should be sufficiently strong that it does not breakdown into small particles in the gasifier.

The MDF dust has moisture content of $2-5 \%$, and is much lower than dried timber which is in the region of $12-18 \%$. Therefore MDF dust is potentially a good candidate for gasification and should produce a good quality fuel gas. Additionally, if water or water-based additive is required in order to make good quality briquettes then there is a good margin to work with. At this moisture content the calorific value of the MDF dust is about $18.5 \mathrm{MJ} / \mathrm{kg}$, which is what would be expected for a wood based feedstock.

It has already been mentioned that it is important for this type of gasifier that a good solid charcoal block is produced. To simulate this process MDF dust briquettes of different density and size were carbonised in a controlled electrical carbonisation furnace. Analys is of the carbonised samples indicates that, provided the right density is achieved, the MDF dust briquettes will have the required mechanical strength, integrity, and thermal value for the gasification process.

\section{Survey of Equipme nt for Producing MDF Dust Pellets}

Within the wood working industry a very wide range of pelletising and briquetting machines are available. They are primarily designed for standard wood chips and dust that has been produced by the industry over several decades. A list of potential briquetting/pelletising machine suppliers and manufacturers was obtained from an industry-based magazine called "Wood Machining News", from internet searches and 
from a document called "Briquetting Biomass" obtained through industry links in Sweden. The possible manufacturers are listed as follows:

- Polytechnik -Austria

- Comafer-Italy

- Bogma-Sweden

- Kahl-Germany

- Spanex-Germany

- Fuchs-Germany

- Holzmag- Germany

- Acosta-Italy

- BMD Biomass-Belgium

- Weima-Germany

- Mecado-France

- PLC Products-England

The above manufacturers were contacted to ascertain their ability to briquette MDF dust. Each of the manufacturers claimed that processing MDF dust would not be a problem and each claimed that they had previous experience of the material and were willing to test the material. To prove the manufacturer's claims, $50 \mathrm{~kg}$ of MDF dust was sent to each of them. The results of this initial trial were very disappointing. Over $75 \%$ of the manufacturers decided that the dust was unsuitable for their individual machine design, due to the dust particle size and the dryness of the material.

Results from the remaining three manufacturers were more promising as solid samples were returned after 6 weeks. The three manufacturers were:

- Kahl

- Fuchs

- $\quad$ PLC Products

The samples returned from Kahl, based in Hamburg Germany were successfully pelletised MDF dust. The pellets were 5-6 mm in diameter and 13-15 mm in length. The pellet was very hard with a glazed surface, which allowed the pellet to be handled quite roughly without any fine dust breaking away. Kahl claimed to have added water to the dust until the moisture content was approximately $14 \%$. The material was heated as it was formed into the pellet due to the extrusion process and the temperatures recorded were in the region of $80^{\circ} \mathrm{C}$.

The samples returned from Fuchs based in Kirchen, Germany, were not as well formed. The samples were in the region of $60 \mathrm{~mm}$ diameter and $60-80 \mathrm{~mm}$ in length. The pellets were very crumbly and some of the samples had actually turned back into loose dust during transit from the test factory, which was in France. This was unfortunate, as the basic size of the pellet was within the size range specified.

The sample returned from PLC Products based in Suffolk, England was very good. It was a $105 \mathrm{~mm} \times 105 \mathrm{~mm}$ square cross-section $350 \mathrm{~mm}$ in length. The outer surface of the briquette was covered in loose dust that was easily removed but the centre was quite dense and solid. There was a distinctive smell from the sample that was similar to that from the MDF board production line. PLC Products claimed to have added water to the dust to raise its moisture content to around 12-15\%. This, along with the heat generated in the extrusion tube, caused the material to turn into a 
semi-plastic state and bond together successfully. The temperatures involved were in the region of $65-75^{\circ} \mathrm{C}$.

Both of the manufacturers that were able to produce a solid pellet/briquette had added water to the dust. The water mist and dust was mixed thoroughly, until mo isture content of $12-14 \%$ was achieved. It may be that at the temperatures generated in the briquetting machine the water turns to steam and it is the steam that softens the wood and allows the natural lignin in the MDF dust to bind the particles together. The temperatures achieved for both processes were in the region of $65-85^{\circ} \mathrm{C}$ and it is also thought that some of the resin used in the original manufacture of the MDF board is reactivated which also helps to bind the dust into a solid product, similar to the MDF board itself. The cost and output characteristics of the two mach ines are compared below:

\begin{tabular}{|c|c|c|c|c|c|}
\hline Manufacturer & $\begin{array}{c}\text { Plant } \\
\text { cost }\end{array}$ & $\begin{array}{l}\text { Briquette } \\
\text { size }\end{array}$ & $\begin{array}{l}\text { Output per } \\
\text { hour }\end{array}$ & $\begin{array}{c}\text { Density } \\
\text { of } \\
\text { product }\end{array}$ & $\begin{array}{l}\text { Suitability } \\
\text { for project }\end{array}$ \\
\hline Kahl & $£ 46,500$ & $\begin{array}{l}\text { Diameter } \\
5-6 \mathrm{~mm} \text {; } \\
\text { Length } \\
13-15 \mathrm{~mm}\end{array}$ & $\begin{array}{c}200 \mathrm{~kg} \\
\text { maximum }\end{array}$ & $\begin{array}{c}600- \\
780 \\
\mathrm{~kg} / \mathrm{m}^{3}\end{array}$ & $\begin{array}{l}\text { Too small for } \\
\text { gasification }\end{array}$ \\
\hline PLC Products & $£ 15,000$ & $\begin{array}{l}105 \mathrm{~mm} x \\
105 \mathrm{~mm} \\
\text { Length } \\
\text { variable }\end{array}$ & $\begin{array}{c}175 \mathrm{~kg} \text { per } \\
\text { nozzle } \\
\text { Max. } 4 \\
\text { nozzles }\end{array}$ & $\begin{array}{c}500- \\
800 \\
\mathrm{~kg} / \mathrm{m}^{3}\end{array}$ & $\begin{array}{l}\text { Above the size } \\
\text { range for } \\
\text { gasification. } \\
\text { May need cut } \\
\text { into quarters. }\end{array}$ \\
\hline
\end{tabular}

It was decided that further trials would be carried out on the PLC Products B10 Bio-Compactor machine, as it was the only company with the potential to achieve the results required. If the results were positive a mach ine would be purchased. MDF dust (400 kg) was tested at PLC Products premises. The dust was mixed with water spray until the moisture content was reading $14 \%$. This was accurately measured with a digital meter. The material was tested in the B10 Bio-Compactor machine, which was very basic in design, but produced a 3 metre length of solid bonded MDF dust, $105 \mathrm{~mm} \times 105 \mathrm{~mm}$ square. The log travelled along a cooling rail and then through a break-off ramp, which could be set at various angles to determine the length of briquette. The entire $400 \mathrm{~kg}$ sample was put through the B10 Bio-Compactor, and it was all successfully bonded. The B10 Bio-Compactor machine was connected to the back of an agricultural tractor, using the rear output shaft to drive the machine. The mach ine for commercial use is driven using an $11 \mathrm{~kW}$ electric induction motor. 
The B10 Bio-Compactor is very simple in operation as follows:

- The MDF dust with added water is fed into a hopper.

- At the bottom of the hopper is a rotary feeder, which controls the addition of MDF dust into the main auger.

- The main auger forces the dust into a tapered nozzle. This tapered nozzle generates a back pressure in the auger stainless steel barrel and it is at this point that the dust is heated up and bonded together under pressure.

- The angle of the tapered nozzle can be adjusted manually to provide the correct back pressure for compaction.

- The speed of the rotary feeder under the storage hopper is adjusted in order to keep the temperature in the auger screw at about $65-75^{\circ} \mathrm{C}$.

- It is this combination of rotary feeder speed and back pressure which generates the correct conditions required to produce good solid briquettes. To help optimise the rotary feeder speed an intelligent programmable logic controller is used.

- As the material travels through the tapered nozzle the heat generated in the auger barrel is dissipated through cooling vanes on the tapered nozzle.

- At the open end of the tapered nozzle the solid briquette emerges. The s urface temperature may be as high as $50^{\circ} \mathrm{C}$ at this point.

- The briquette travels inside a cooling rail for a further 3 meters and into the break off ramp, where the briquette breaks off to the desired length and is ready for use.

As the trials at PLC Products premises had been successful and it was therefore decided to purchase the B10 Bio-Compactor with two nozzles. During the initial trials the B10 Bio-Compactor did not perform as previously witnessed at PLC Products. A number of problems were experienced as follows:

- The B10 Bio-Compactor would not bond the MDF dust as it was not generating sufficiently high temperature.

- The briquettes jammed in the extrusion nozzle stalling the drive motor.

- The mach ine operator was unable to maintain a constant temperature.

- There was a mechanical failure of the thrust bearing.

- There was a failure of the seal on the auger screw.

- There was a weld failure on the main machine frame.

- For short periods the machine ran well and produced good briquettes, but then suddenly it would jam and live steam would blow out.

- The flapper valve, which was made of plastic, shrank due to contact with live steam.

- Machine caught fire, but sustained only minor damage.

Once these problems were eliminated, the machine was rebuilt and run again using the manufacturers notes and handbook. Yet again problems were experienced with material jamming or no material bonding, taking place. Different binding agents were discussed, and PVA wood glue was tested to see if the results could be improved. The PVA wood glue was added to the water at a strength of $20 \%$ PVA, $80 \%$ water. This was applied to the dust in the normal way to raise the moisture content up to the $14 \%$. The B10 Bio-Compactor worked well with this binding agent. The machine produced a consistent, 3 metre long briquette. In total $1000 \mathrm{~kg}$ of dust 
was tested within a 2-day period. The main factor in getting the B10 Bio-Compactor fully functional was to gain experience in its correct operation.

With regard to the use of these briquettes in the gasifier, the briquettes produced by the B10 Bio-Compactor are $105 \mathrm{~mm}$ x $105 \mathrm{~mm}$ square and 3 metres in length. The briquettes must be cut into quarter for use in the gasifier. The standard briquette using only water as the binding agent mixed at $14 \%$ moisture content produces a solid block with a density of $700-780 \mathrm{~kg} / \mathrm{m}^{3}$. Briquettes made with the PVA wood glue and water as the binding agent produce a solid block with a density of $850-925 \mathrm{~kg} / \mathrm{m}^{3}$. At these densities the carbonisation performance of the MDF dust briquettes should be satisfactory. Therefore, there is the potential to produce briquettes from MDF dust using the B10 Bio-Compactor, which meet the requirements for the gasifier from a size, mo isture content and carbonis ation performance point of view.

\section{Gasification Trials of MDF Briquettes}

\section{(i) Feedstock for gasification trials}

Due to the problems experienced during the initial testing of the B10 Bio-Compactor, it was decided that it was very unlikely that sufficient briquettes could be made within the time frame of this project to perform gasification trials using briquettes from the B10 Bio-Compactor. However, the initial trials had shown, if only for short periods, that it was possible to make briquettes of sufficiently high density that they would give satisfactory carbonisation performance and therefore there was a good chance that they could be gasified in a fixed bed gasifier. The briquettes that were produced by the B10 Bio-Compactor had a density very similar to the original MDF board. MDF dust is the same material as MDF board and therefore there is no reason to believe that the gasification performance of MDF off-cuts will be any different from briquetted MDF dust. Therefore, the decision was taken to perform the gasification trials using off-cuts fro m MDF board.

\section{(ii) Description of fixed bed gasifier}

The gasifier used for the trials was the Rural Generation Ltd (RGL) wood gasifier located at the Brook Hall Estate near Londonderry. This was originally installed to a design specification supplied by Prof. J.Martin of the Universite Catholique de Louvain in Belgium. Numerous alterations have since been undertaken on almost every aspect the gasifier installation. In particular most recently, the hearth of the gasifier has been replaced by new hearth designed by Fluidyne Gasification, New Zealand. The basic design of the installation may be summarised as follows:

- $\quad$ pressurised down-draft gasifier operating on a 18-20 hour batch feed system;

- blast tube and cyclone dry gas cleaning system;

- $\quad$ water bubbler cooling and cleaning system (used only as required);

- air-to-gas heat exchanger and water condenser;

- $\quad$ cold-gas particulate filter;

- $\quad$ air/gas mixing system;

- electrical power generation via dual-fuel diesel engine and asynchronous generator;

- heat recovery from engine coolant and exhaust. 
The system operates as follows:

- Dried riddled wood chip is fed into the $12 \mathrm{~m}^{3}$ storage hopper above the hearth of the gasifier, and the lid of the hopper is subsequently sealed.

- Gas exit valves are then closed to allow modest initial pressurisation of the hopper. This allows the control system to check for leakage.

- The test pressure is then released, and the gasifier ignited using an automatic propane ignition system.

- At the same time, process air is provided at an appropriate rate and at a precisely defined location in the gasifier hearth. This supports initial combustion of the wood char in the hearth, and production of wood gas will follow as the temperature of the hearth and of its contents stabilises.

- It is primarily the geometrical design of the gasifier hearth that determines the success of the gasification process. For power generation with engines, it is especially important to ensure that the levels of tar in the gas are extremely low and carefully controlled.

- "Engine-quality" gas should be available in most circumstances in less than 10 minutes from gasifier ignition.

- The hot gas leaving the gasifier contains fuel gases in the form of hydrogen, carbon monoxide and a small amount of methane. The remainder of the gas will be nitrogen, carbon dio xide and water vapour. In addition, there will be some fine carbon and particulate ash, which is mostly removed by a series of cyclones.

- A water bubbler system is also included at this point in the gas-conditioning process for cooling and scrubbing of the gases. Water bubbling is not always necessary, and the unit is now used only as required.

- The partially cooled and cleaned gas then proceeds to an air-to-gas heat exchanger, where the temperature of the gas will drop to close to ambient temperature.

- A proportion of the water in the gas is also removed through condensation at this heat exchanger, and facility is included in the system to allow the removal and safe disposal of the condensate.

- The quantity of water condensate per hour will depend very largely on the mo isture content of the fuel.

- The fully cooled gas passes through one further particulate filter prior to mixing with air near the inlet man ifold of the diesel engine. The proportions of the air and gas must be carefully controlled to suit the power output and supplementary fuel percentages and to ensure efficient engine operation.

The conversion of the gas heating value to electrical and thermal power is achieved at Brook Hall via a standard Iveco diesel engine. The engine has 13.8 litre capacity, and drives an asynchronous generator at approximately $1530 \mathrm{rev} / \mathrm{min}$. At this speed, the generator output power is approximately $100 \mathrm{~kW}$. This electrical power is supplied to the local electricity grid through the auspices of a Non-Fossil Fuel Obligation (NFFO) contract. The unit at Brook Hall has been designed to provide both heat and power. Heat recovery from the engine is achieved using two heat exchangers, one in the water coolant circuit and one on the engine exhaust 
Gasification of Waste Medium Density Fibreboard for Power Generation

system. Thermal power is then distributed for grain drying, wood fuel drying and for space heating of dwellings across the Estate.

A new control system for the Brook Hall gasifier/engine unit was installed within the last 8-10 months. This allows for automated running of the plant along with automatic shutdown as required. In the case of any automatic shutdown, the reas on for the stoppage is recorded. Several operations still have a manual input on the Brook Hall system, in particular the fuel feed system, the ash removal system and the gasifier start-up and ignition system. This reflects the status of the unit as a development unit for Rural Generation Ltd. It would however now be possible to consider automation of all these aspects of plant operation in subsequent installations as required.

It was considered important that, as the feedstock was being changed from coppiced willow to MDF briquettes, the quality of the fuel gas produced should be monitored. Therefore, as part of this project, an on-line gas analyser was installed in the feed from the gasifier to the diesel engine, downstream of the cooler. This enabled the $\mathrm{CO}, \mathrm{CO}_{2}$ and $\mathrm{H}_{2}$ levels to be recorded.

\section{(iii) Performance of MDF on RGL gasifier}

MDF is a form of processed wood containing $82 \%$ softwoods, $8-12 \%$ urea resins and 6-8\% water. There are also small traces of paraffin wax and a very small trace of "free" urea formaldehyde. MDF is potentially an excellent fuel. It is dry, of high calorific value, and (in solid form) has very high density (specific gravity up to 0.99). The gasification team therefore entered into the MDF trails with high expectations of extremely good results.

In the event, the main difficulty in conducting the trials was presented by the size of the Brook Hall fuel hopper. In order to facilitate batch plant operation of willow coppice fuel, the hopper was designed with a volume of approximately $12 \mathrm{~m}^{3}$. The MDF blocks were found to have a bulk density of around $395 \mathrm{~kg} / \mathrm{m}^{3}$. The amount of MDF block material required to fill the fuel hopper would therefore have been around 4.8 tonnes. In practice, only appro ximately 3 tonnes was available and therefore the remainder of the hopper was then filled with wood chip as per normal practice in order to minimise the risk of gas ignition in the fuel hopper. In all, the gasifier operated for approximately 8 hours. The following results were recorded for the RGL gasifier while operating on MDF:

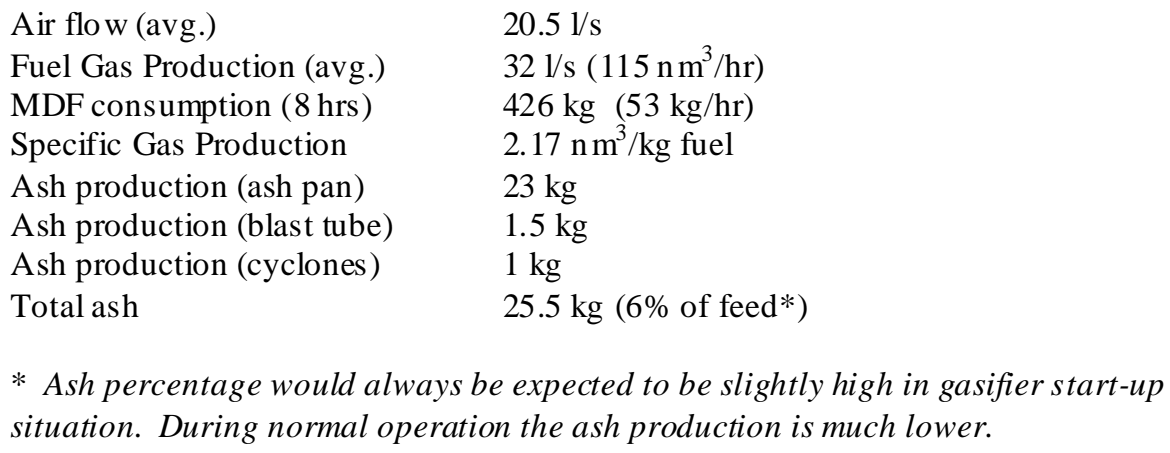

* Ash percentage would always be expected to be slightly high in gasifier start-up situation. During normal operation the ash production is much lower. 
B.C. Williams, D. McIlveen-Wright and S. Rezvani

The following average fuel gas analysis figures $(\% \mathrm{v} / \mathrm{v})$ were also of considerable interest:

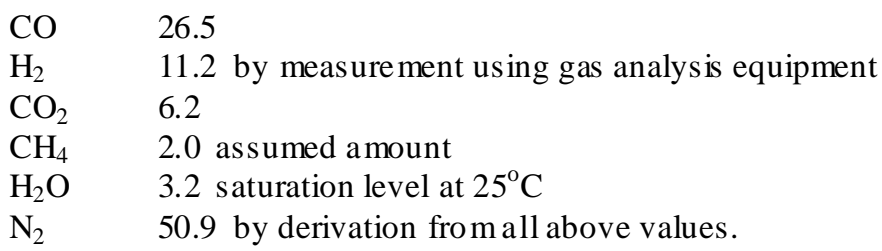

This gives a net calorific value for the gas (LCV) of $4.8 \mathrm{MJ} / \mathrm{nm}^{3}$, almost identical to the figure obtained at Brook Hall for producer gas derived from hardwood chip fuel (see accompanying performance chart). This represents a near-optimum LCV for engine-compatible tar free producer gas. As compared with wood chip, it may be seen that the gas from MDF contains more $\mathrm{CO}\left(\sim 4 \%\right.$ higher), less $\mathrm{CO}_{2}(\sim 4 \%$ less $)$ and similar $\mathrm{H}_{2}$. This can almost certainly be attributed to the lower moisture content of the fuel.

\section{(iv) Performance of MDF fuel gas in diesel engine}

During the MDF gasification trials a mixture of diesel and MDF fuel gas was fed to the diesel engine. This is the normal practice for these types of engines in order to maintain smooth and efficient combustion. On a thermal input basis the diesel represents about $13 \%$ of the total thermal input. No problems were experienced with the diesel engine when changing over from $100 \%$ diesel to $87 \%$ fuel gas $/ 13 \%$ diesel. The exhaust emissions from the engine were checked using a Land exhaust gas analyser. The following observations were made.

\section{$N O_{x}$ emissions}

When operating on $100 \%$ diesel the $\mathrm{NO}_{\mathrm{x}}$ emissions varied between $700 \mathrm{ppm}$ and $1600 \mathrm{ppm}$. On wood chip fuel gas the $\mathrm{NO}_{\mathrm{x}}$ emissions dropped significantly to between $50 \mathrm{ppm}$ and $70 \mathrm{ppm}$. This may be due to lower temperatures in the combustion chamber when operating on wood chip fuel gas leading to less thermal $\mathrm{NO}_{\mathrm{x}}$ generated. However, with MDF fuel gas there was only a small reduction in $\mathrm{NO}_{\mathrm{x}}$ emissions, by 200-300 ppm NO . It may be in this case that although there is a reduction in thermal $\mathrm{NO}_{\mathrm{x}}$ emissions, for the same reasons as above, with MDF fuel gas there may be significant quantities of ammonia present from the MDF resins. In the combustion chamber the ammonia will be converted to $\mathrm{NO}_{\mathrm{x}}$ and therefore $\mathrm{NO}_{\mathrm{x}}$ is increased.

The Environment and Technology Support Unit (ETSU) has indicated that fuel gas produced from the gasification of MDF fuel may contain a significant proportion of ammonia - perhaps up to $2 \%$ volume. In such a case, the fuel value of the gas would not be appreciably affected. Ammonia could however cause problems by its smell, and also by reacting adversely with any brass or copper fittings in the gas supply line or in the engine. We were not equipped in our own short tests to confirm or deny the presence of ammonia, nor to quantify its presence or effect. There was certainly a mild distinctive smell from the MDF producer gas, and this could well have been caused by the presence of ammonia. It would nonetheless be difficult to 
believe that a proportion as high as $2 \%$ could have been present, bearing in mind the very mild odours which were observed.

Furthermore, advice obtained from the Chemical Engineering Department at QUB during the course of this project would indicate that ammonia molecules should not be able to survive firstly the high temperatures of the combustion zone in the hearth, and then secondly the reducing atmosphere of the gas production zone. We therefore suspect that the degree of production of ammonia from MDF blocks in a gasification process may depend very strongly on the detailed design of the particular gasifier. Further background research or small-scale tests on this aspect of MDF gasification may eventually be required.

\section{CO emissions}

Initial indications are that the $\mathrm{CO}$ emissions from the diesel engine are higher when running on wood chip fuel gas compared to running on diesel only. Likewise the emissions from MDF fuel gas may be higher still due to the higher $\mathrm{CO}$ level in the fuel gas. However, insufficient information is available to be definite about this and further research on the combustion of fuel gas from wood gasification in a diesel engine may also be required.

$\mathrm{CO}_{2}$ emissions

MDF is a wood based product and is therefore a renewable energy source. If it is used to generate electricity it would replace electricity purchased from the grid. Most of the electricity in Northern Ireland is generated in fossil fuel fired power stations and last year on average there was $0.73 \mathrm{~kg}$ of $\mathrm{CO}_{2}$ emitted for every $\mathrm{kWh}$ of electricity generated. If a $100 \mathrm{kWe}$ RGL CHP system was installed, then the annual electricity generated would be approximately $800,000 \mathrm{kWh}$. Therefore, this would reduce the global $\mathrm{CO}_{2}$ emissions by $580 \mathrm{t} / \mathrm{a}$.

\section{Conclusions}

The following are the main conclusions from this project.

- Although many equipment manufacturers claim to be able to pelletise or briquette MDF dust, only two were able to prove this capability, namely PLC Products and Kahl.

- Within the specification laid down for the briquettes to be used in the RGL gasifier, only the PLC Products briquettes were satisfactory.

- Good quality briquettes could not be produced consistently for any extended period. This was due in part to a lack of experience of operating the B10 BioCompactor and in part to mechanical failures.

- In order to provide MDF briquettes for the gasification trials at RGL it was decided to use MDF off-cuts sawn to the correct size. The project team was happy that these MDF off-cuts would possess very similar properties to the briquettes produced by the B10 Bio-Compactor and would therefore give a very good indication of their gasification behaviour.

- The gasification trials at RGL were very successful, with 8 hours continuous operation without problems. The lower calorific value of the fuel gas produced 
was $4.8 \mathrm{MJ} / \mathrm{nm}^{3}$ which is almost identical to the figure obtained at RGL for producer gas derived from hardwood chip fuel. This represents a near-optimum LCV for engine-compatible tar free producer gas.

- On line analysis equipment, installed as part of this project, showed that compared with hardwood chip the fuel gas from MDF contains more $\mathrm{CO}(\sim 4 \%$ higher), less $\mathrm{CO}_{2}(\sim 4 \%$ less $)$ and similar $\mathrm{H}_{2}$. This can almost certainly be attributed to the lower moisture content of the MDF fuel.

- During the MDF gasification trials a mixture of diesel and MDF fuel gas was fed to the diesel engine. This is the normal practice for these types of engines in order to maintain smooth and efficient combustion. On a thermal input basis the diesel represents about $13 \%$ of the total thermal input. No problems were experienced with the diesel engine when changing over from $100 \%$ diesel to $87 \%$ fuel gas $/ 13 \%$ diesel.

- The exhaust emissions from the engine were checked using a Land exhaust gas analyser. When operating on $100 \%$ diesel the $\mathrm{NO}_{\mathrm{x}}$ emissions varied between $700 \mathrm{ppm}$ and $1600 \mathrm{ppm}$. When operating on hardwood chip derived fuel gas the $\mathrm{NO}_{\mathrm{x}}$ emissions dropped significantly to between $50 \mathrm{ppm}$ and $70 \mathrm{ppm}$. This may be due to lower temperatures in the combustion chamber when operating on hardwood chip fuel gas leading to less thermal $\mathrm{NO}_{\mathrm{x}}$. However, with MDF derived fuel gas there was only a small reduction in $\mathrm{NO}_{\mathrm{x}}$ emissions. It may be that there are significant quantities of ammonia present from the MDF resins, which will be converted to $\mathrm{NO}_{\mathrm{x}}$ in the combustion chamber. In itial indications are that the $\mathrm{CO}$ emissions from the diesel engine are higher when running on hardwood chip fuel gas compared to running on diesel only. Likewise the emissions from MDF fuel gas may be higher still due to the higher CO level in the fuel gas. However, insufficient information is available to be definite about this and further research on the combustion of fuel gas from wood gasification in a diesel engine may also be required

- MDF is a wood based product and is therefore a renewable energy source used to generate electricity as a replacement for electricity purchased from the grid. Most of the electricity in Northern Ireland is generated in fossil fuel fired power stations and last year on average there was $0.73 \mathrm{~kg}$ of $\mathrm{CO}_{2}$ emitted for every $\mathrm{kWh}$ of electricity generated.

\section{Acknowedgements}

This project was partly funded by the European Commis sion through the INTERREG Programme. I would like to thank Mr Lawrence Foye, from the Department of Enterprise, Training and Investment in Belfast, for his support during this project. I would also like to acknowledge the support and assistance provided by SAM Ltd, Rural Generation Ltd, Innovation Technologies Ireland Ltd and The Queen's University of Belfast (QUB). 